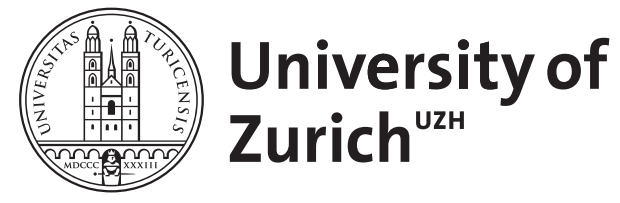

Zurich Open Repository and Archive

University of Zurich

University Library

Strickhofstrasse 39

CH-8057 Zurich

www.zora.uzh.ch

Year: 2013

\title{
Some unique superconductive properties of cuprates
}

Müller, K A

DOI: https://doi.org/10.1007/s10948-012-1954-x

Posted at the Zurich Open Repository and Archive, University of Zurich

ZORA URL: https://doi.org/10.5167/uzh-156199

Journal Article

Published Version

Originally published at:

Müller, K A (2013). Some unique superconductive properties of cuprates. Journal of Superconductivity and Novel Magnetism, 26(4):743.

DOI: https://doi.org/10.1007/s10948-012-1954-x 


\title{
LETTER
}

\section{Some Unique Superconductive Properties of Cuprates}

\author{
K.A. Müller
}

Received: 27 November 2012 / Accepted: 1 December 2012 / Published online: 30 December 2012

(C) Springer Science+Business Media New York 2012

Copper oxides are the only materials that show transition temperatures, $T_{\mathrm{c}}$, above the boiling point of liquid nitrogen, with a maximum $T_{\mathrm{c}}^{\mathrm{m}}$ of $162 \mathrm{~K}$ under pressure. Their structure is layered, with one to several $\mathrm{CuO}_{2}$ planes, and upon hole doping, their transition temperature follows a domeshaped curve with a maximum at $T_{\mathrm{c}}^{\mathrm{m}}$. In the underdoped regime, i.e., below $T_{\mathrm{c}}^{\mathrm{m}}$, a pseudogap $T^{*}$ is found, with $T^{*}$ always being larger than $T_{\mathrm{c}}$, a property unique to the copper oxides. ${ }^{1}$ In the superconducting state, Cooper pairs (two holes with antiparallel spins) are formed that exhibit coherence lengths on the order of a lattice distance in the $\mathrm{CuO}_{2}$ plane and one order of magnitude less perpendicular to it. Their macroscopic wave function is parallel to the $\mathrm{CuO}_{2}$ plane near $100 \% d$ at their surface, but only $75 \% d$ and $25 \% s$ in the bulk, and near $100 \% s$ perpendicular to the plane in YBCO. There are two gaps with the same $T_{\mathrm{c}}$ [2]. As a function of doping, the oxygen isotope effect is novel and can be quantitatively accounted for by a two-band vibronic theory [3] near $T_{\mathrm{c}}^{\mathrm{m}}$, and underdoped below it till $T_{\mathrm{c}}=0$ by a formula valid for (bi)polarons [4]. These cuprates are intrinsically heterogeneous in a dynamic way. In terms of quasiparticles, Jahn Teller bipolarons are present at low doping, and aggregate upon cooling [1], so that probably ramified clusters and/or stripes are formed, leading to a more Fermi-liquid-type behavior at large carrier concentrations above $T_{\mathrm{c}}^{\mathrm{m}}$.

\section{References}

1. Müller, K.A.: J. Phys. Condens. Matter 19, 251002 (2007)

2. Khasanov, R., Shengelaya, A., et al.: Phys. Rev. Lett. 98, 0570007 (2007)

3. Keller, H., Bussmann-Holder, A., Müller, K.A.: Mater. Today 11, 38 (2008)

4. Weyeneth, S., Müller, K.A.: J. Supercond. Nov. Magn. 24, 1235 (2011)

${ }^{1}$ For an overview see [1].

K.A. Müller $(\varangle)$

Physics Institute, University of Zürich, 8057 Zürich, Switzerland

e-mail: irmamf@bluewin.ch 